PII S0364-6408(97)00020-3

\begin{tabular}{c}
\hline THE FIRST ELSEVIER ELECTRONIC SUBSCRIPTIONS CONFERENCE \\
OCTOBER 17-18, 1996 \\
HEEMSKERK, THE NETHERLANDS
\end{tabular}

\title{
PEAK: PRICING ELECTRONIC ACCESS TO KNOWLEDGE
}

\author{
JEFFREY K. MACKIE-MASON \\ Associate Professor of Economics and Information \\ University of Michigan \\ Ann Arbor, MI 48109-1220, USA \\ Internet: jmm@umich.edu
}

ALEXANDRA L. L. JANKOVICH

Associate Marketing Director

Elsevier Science, B.V.

Molenwerf 1

Amsterdam

The Netherlands

Internet: a.jankovich@elsevier.nl

\section{INTRODUCTION}

Dramatic increases in the capabilities of computers and communication networks have fomented revolutionary thoughts (if not the revolution itself) in the scholarly publishing community. Much attention is focused on upstart electronic-only journals, and whether they will successfully displace or competitively discipline the journals managed by traditional professional publishers. Meanwhile, traditional publishers are developing and testing schemes for electronic access to their body of literature. This paper concerns a controlled field experiment to investigate the effects of product bundling and pricing structures for electronic access to scholarly literature. MacKie-Mason and his colleagues at the University of Michigan are implementing the field experiment at the time of this writing. The host service team is receiving and preparing digital content. The marketing team is recruiting trial participants. The PEAK team is finalizing the details of the bundling and pricing schemes, and the technical structures necessary to provide authorization and authentication, accounting, and other services are being developed. However, the experimental treatment and data collection have not yet begun.

The primary research objective is to generate rich empirical evidence on user behavior and provider results with various bundling schemes and price levels. In this our work will complement 
the more theoretical research of Bakos and Brynjolfsson [1] and Chuang and Sirbu [2]. However, authors in the bundling literature, including these recent papers, have restricted their models to rather simplified bundling structures. Although we are severely limiting the design of the trial in order to obtain good data and testable hypotheses, for both practical and intellectual reasons our experimental design calls for bundling structures that have not yet been explored theoretically. We intend to extend the theoretical work to our more realistic and general structures [3].

In this paper we first provide background on the market economics of the publishing business and describe some important economic problems facing both research libraries and scholarly journal publishers. We then explain how the opportunity provided by electronic access to use innovative bundling and pricing structures offers some hope of easing the library and publisher problems. New bundling and pricing schemes can uncover new value from both old and new scholarly content. In the next section we describe our utility-theoretical framework for analyzing the consumer response to the trial conditions, and then briefly survey some related literature on bundling and nonlinear pricing. In the final section, we describe the main features of the experiment and the rationale behind the design.

\section{ECONOMICS AND ELECTRONIC PUBLISHING}

\section{Publishing Economics}

Publishing is a value-adding business. This point has been underemphasized by some recent authors. Utopians have suggested that by putting technology in the hands of authors, for-profit publishers can and inevitably will be bypassed [4]. Electronic scholarly journals will arise that are edited, produced, marketed, and distributed by scholars working in the service of scholarship, rather than by professional publishers in the service of profit (e.g., Harnad [5] and Odlyzko [6]). This striking view conflates two issues: whether or not publishing as a business adds value to authorship, and the industrial organization of the business of publishing. Of course, the way in which value is added and the structure of costs underlying that value may determine the efficient and sustainable organization of the industry. Nonetheless, sources of value and industrial organization must be examined separately when technology, costs, and service offerings are drastically changing.

Publishing adds significant value to authoring. The digital revolution is changing sources and amounts of value added, but not eliminating it. The costs of some functions are decreasing rapidly, but other costs are increasing. Meanwhile, as new information services are developed, new opportunities for publishing value added are also created. Publishers provide many services to authors and readers. For example, they perform copyediting, proofing, typesetting, layout, printing, and binding. The publisher chooses and controls the quality of the medium (whether paper stock, SGML tagging, etc.) and production of offprints and supplemental bundles (e.g., CD-ROMs). The publisher also handles fulfillment: billing, accounting, and distribution. Even electronic journals require distribution skill: server administration, backup maintenance, and network management. And even electronic journals have costs that must be covered through some mechanism: publishers specialize in cost management and recovery [7]. Perhaps most importantly, the publisher brings readers to the author: the marketing function. It is quite evident that scholarly journal authors are not writing for direct cash compensation, but to obtain readership (from which indirect compensation may follow). Good scholars are good at research, not at finding readers [8].

There are at least two implications from the considerable value publishing adds to authorship:

1. There is likely a role for an independent publishing industry; and,

2. Competition should ensure efficient provision of publishing services. 
We expect to see independent publishing because there is enough value added separate from authorship itself that specialization will continue to be efficient: authors aren't the most fit to provide publishing services. If transactions costs between authors and publishers were high, then we might expect integration into single organizations, but there is no obvious reason to think such transactions costs are important. There are some clear economies of scale that publishers can achieve, however, such as in the employment of typesetters, copy editors, and printers, which are an advantage for large, multi-journal publishers.

We believe that our second claim is the more important: whatever organizational form the industry takes, competition should lead to efficient provision of publishing services. The argument here is quite fundamental and well understood in the economics of industry: there are low entry barriers and few proprietary advantages to participation in publishing. One type of entry barrier is proprietary control over distinctive intellectual property. It might seem that control over intellectual property is a prevalent characteristic of scholarly publishing: authors' work, over which the publisher usually has copyright, is unique and valuable. Clearly, different research articles are valued differently, or we wouldn't see such wide variation in prices and reputations among journals within similar fields and with similar production quality. However, the key to understanding the steady-state performance of the publishing industry is to recognize that publishers don't initially control content: authors do. Publishers who are currently more successful at bringing readers to authors might have an advantage in bargaining for the best new content, but they do not have control. If the publisher charges too much to readers or degrades production quality, then another publisher can easily step up and offer authors a journal that will be more accessible or more appealing to readers. Of course, reputations rarely depreciate overnight. Thus, a publisher who produces a journal that is considered the best in its field is likely to maintain its subscription base and readership for at least some time. However, academic editorships turn over relatively frequently, and publishers have to compete to attract new editors, who will pay attention to quality and pricing of the journal. Likewise, libraries and other subscribers do not mindlessly subscribe to every journal. Indeed, there are very few journals, even among the very best, to which every potential subscriber subscribes. There are always marginal purchasers who are willing to forego a subscription if the price is a bit too high or the production quality a bit too low.

The natural competitiveness of the market for publisher services is quite important. First, it is a well-known result in economics that if the market participants behave competitively, then the outcome will maximize consumer plus producer surplus [9]. Surplus is the excess between value received and price paid. The consumers in the market for publishing services are both readers and authors; the producers are the providers of publishing services. However, competition also ensures that the producers will not receive excess profits. That is, producers will generally only receive enough to cover their costs (including a competitive rate of return on invested capital). The rest of the maximized surplus will be enjoyed by readers and authors. A competitive market also has the property that it is Pareto efficient, which means that no alternative allocation of goods and services can make at least one agent better off without making at least one agent worse off. In more colloquial terms, the performance of a competitive market in publishing services is quite attractive: readers get the best combination of quality, price, and quantity possible given the technology and costs of production, and authors get the best readership possible. When new sources of value arise (such as searching over a digital document database), much of the value ultimately accrues to consumers. Of course, at any given moment, a market may not be performing optimally, but in the absence of structural problems (e.g., barriers to entry and externalities) we have a lot of evidence that competitive markets perform very well on average, over time. Many readers will no doubt wonder whether this optimistic view is justified, given apparent problems for readers and authors in the scholarly publishing business. We now discuss some of these problems. 


\section{Comparison Between Paper and Electronic Publishing}

Introducing electronic publishing to the print industry raises the usual problems of a new business: new investments with uncertain revenues and new prototype testing with customers to discover the real value-added products. Electronic publishing is expected to co-exist with print (rather than entirely replace it). Therefore, there is a need to transform the print business in response to production and demand interactions with the electronic business. The simultaneous development of electronic publishing and re-engineering of the traditional print business make the new business problems especially severe. Some concerns are specific to the publishing business. For example, for copyrighted documents there are security concerns at both the customer and publisher levels. With Internet technology (with IP addressing as an identifier), it is difficult to establish a watertight security system at the end-user level. Customers, especially librarians, have a different security concern: who (if anyone) will set up a reliable archive for digital-format documents?

Comparing the cost structures of print and electronic publishing depends on the production process used. If the process is completely computer aided, then print and/or electronic products are the outcome. In general, it is difficult to make the comparison because the two products have different value to consumers. Print on paper seems to be preferred to reading on a monitor, at least for complete articles. Electronic publishing facilitates new value-added services, such as hypertext links and social filtering. Adding hypertext links or other electronic-specific features will offset other cost advantages. In either case, the fixed or "first-copy" costs are large relative to the variable or per copy costs. Electronic publishing has significant advantages for both customers and publishers. Customers may gain faster and more convenient access (on the desktop workstation, rather than in the library). Publishers can obtain much more detailed usage data. We now focus specifically on how electronic access may affect two major stakeholder groups: research libraries and publishers.

\section{Electronic Access and Research Libraries}

Research libraries have faced a number of recent difficulties. They are often located in institutions of higher education, which have experienced severe budget pressures. In many cases, centrally provided infrastructure services - such as libraries provide-have borne more than their share of budget reductions. Concurrent with budget reductions, libraries have faced increases in subscription prices. The increasing demand for new services based on digital and network technology has perhaps made matters worse (although also creating excitement for information professionals), as it calls upon already overtaxed human and financial resources. Given this rather dismal set of problems, we should consider what opportunities might be provided by electronic access to scholarly materials. The first effect that many have hoped for is a reduction in service cost. Unfortunately, although some costs are lower when distribution is electronic, these costs tend to represent only a modest fraction of the total costs of publishing. Further, libraries need to make investments in new technology, network distribution, customer support personnel, and file storage systems. We estimate that start-up costs for a digital library host service that handles only 200 journals for local use may run as high as $\$ 100,000$. In any case, even if there are significant cost savings to be made, the question is not very well posed. Electronic access changes both the profile of services available and their quality (which in some cases increases, but in others decreases). Any attempt to compare the costs of paper and electronic publishing must carefully account for these differences in quality and the services provided: the classic "apples and oranges" problem. 


\section{Electronic Access and Publishers}

The fundamental problem facing publishers is clear: high first-copy costs. Odlyzko [10] reports that it costs $\$ 900-\$ 8,700$ to publish a single math article, with a median of $\$ 4,000$. Of this, $70 \%$ is editorial and production first-copy cost: that is, the cost before reproduction and distribution. Thus, most of the cost to be recovered by a going concern is fixed. Pricing at marginal cost will not recover first-copy costs. Competition in publishing, however, creates pressure to price at marginal cost. When most publishers are printing on paper, and thus have similar cost structures, an uneasy equilibrium with prices above marginal cost appears to be stable, possibly supported by significant lags in the movement of editors and journal content between publishers in response to competitive pricing changes. However, the advent of electronic publishing brings a medium with potentially lower first-copy costs. In the U.S. telecommunications industry, local access firms face a similar situation when "bypass" operators who need not pay the fixed costs of universal service are able to offer large customers lower rates for connection to long distance networks. Likewise, in publishing there is an increasing threat from "bypass publishing" [11]. Increased electronic competition pressures print-on-paper publishers to find new ways to recover first-copy costs without loading them all on per copy (or per subscription) pricing. In part, print-on-paper publishers respond to electronic competition by seeking to develop electronic delivery media. They also are investing to develop various new value-added services based on the investment in first-copy scholarly literature creation, in order to share the recovery of fixed costs across more activities. However, these incremental activities involve development expenditures and increase the publisher's risk since the new products are often untested and of uncertain value.

\section{Survey of Pricing and Bundling in Other Industries}

Electronic publishing facilitates flexible usage measurement and recombination of products. As a consequence, a wide range of opportunities is opened for nonlinear pricing and innovative product bundling [12] (See Figure 2). While working on its own pricing and bundling plans, Elsevier Science undertook research on pricing for electronic services in other industries: content, telecommunications, Internet service, etc. Both online and CD-ROM pricing were studied. We describe findings for two relevant industries here:

1. Long distance providers. An historical cycle between flat and variable rates is apparent in the U.S. long distance telecommunications industry (Figure 1). For many years, flat-rate pricing was the preferred method. Over time, knowledge about users, system capabilities for dealing with payments, and the number of competing suppliers increased. Consequently, pricing became more complicated, with extensive differentiation by customer group and usage characteristics. More recently, there has been an apparent customer backlash against the complexity of pricing schemes, and transparent flat pricing has been re-introduced.

2. Online database providers. In the 1970 s and 1980 s, most online database providers used connect time as a price basis. This scheme was easily understood, search costs were easy to calculate, and a wide range of databases could be accommodated. However, users perceived several disadvantages from connect-time pricing: connect time was not easy to predict and thus was difficult to budget; inefficient searchers were penalized; and the value of a system's interactive potential was not realized since connect time discouraged browsing. Meanwhile, users took advantage of technological advancements, such as increased transmission and search speeds, to decrease connect-time costs. In response, several online database providers introduced new pricing schemes in the early 1980s, with variable pricing based on the number of hits, search terms, the type of file search, an up-front access fee, time differentials, 


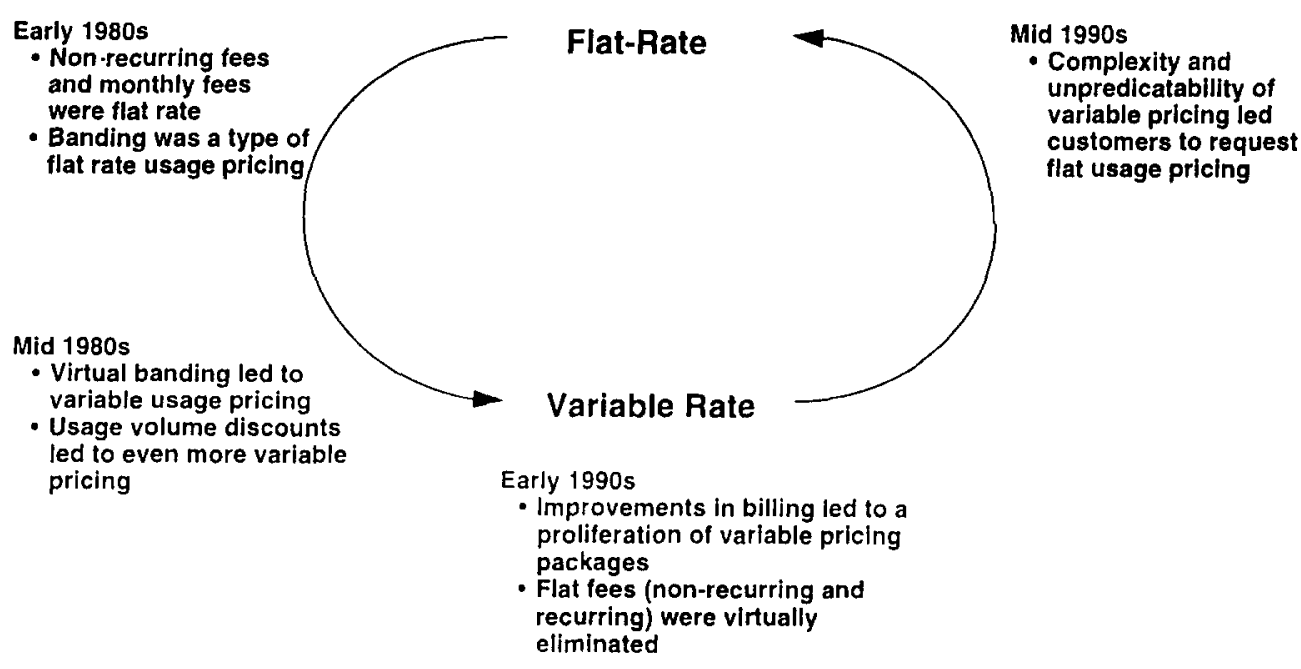

Figure 1. Telecommunications pricing in the U.S.

etc. [13]. The most common schemes today are based on connect hours, offline hits/prints, and online displays. Industry participants expect subscription plans to become increasingly important over the next 5 years.

\section{Opportunities with Electronic Access: Bundling and Nonlinear Pricing}

Although libraries and publishers both face significant problems, some of them the result of developments in electronic access, such access also creates opportunities for dealing with those problems. Electronic access enables both publishers and libraries to engage in new product bundling and nonlinear pricing schemes. The first will often involve unbundling of traditional journal components and then rebundling in a greater variety of packages, some of them customized for customers, or customizable by them. Nonlinear pricing is facilitated by lower transactions costs for fine-grained purchases and feasible direct usage monitoring by the publisher or library.

New bundling and pricing schemes are enabling technologies: they liberate previously unrealized sources of value from existing content and from new value-added services. For example, bundling can do a better job of extracting revenue from users who value the same content differently. Nonlinear pricing can "sort" users by their preference for new services and extract more of their differing values. Publishers earn returns on their innovations that can offset fixed publishing costs. By spreading those fixed costs over more streams of revenue, they can recover them with less quantity distortion and vulnerability to competition. In a competitive publishing environment, consumers get to keep most or all of the newly liberated surplus (excess of value over cost). An example of finding new value from old content would be differential charges to various user types for access to traditional content. Differential charging might be hard to implement for print-on-paper publication because there is little opportunity to observe actual differences in usage. With electronic access, however, it can be possible to distinguish between, say, retrieval of abstracts or bibliographic records vs. retrieval of full text. Since users typically value different uses of content differently, a system of differential charges to recover cost of service can extract more value from a heterogeneous set of uses. There are a variety of different schemes that fall under the 
general rubrics of price discrimination or nonlinear pricing. The general result in the economics literature is that when it is possible to distinguish between different user or usage types, and when resale between parties or uses (arbitrage) is costly or preventable, then nonlinear pricing extracts more value than does uniform pricing.

The simplest example of nonlinear pricing is perfect price discrimination. Imagine that it is possible for the service provider to perfectly observe exactly how much each different transaction is worth to every user and to charge accordingly. Obviously, the service provider is then able to extract the maximum possible revenue to recover costs and support new services. In general, such perfect differentiation is not possible. The key to differential pricing is to find observable characteristics (of users, or their uses of content) that are correlated with their willingness to pay, and then to base charges on the value information that is partially revealed. Electronic access provides an opportunity to observe a variety of such characteristics, such as user type (education, business, subscriber, or occasional, determined from authentication records), use type (immediacy of access to current information, volume, full documents, or components), and quality (display resolution, text only or images, plain text or formatted).

The second type of opportunity is to extract value from new service provision. The literature is full of new services that may be enabled by electronic access. We will summarize a few here just to illustrate the opportunities:

1. Hyperlinks. It is possible to prepare documents with embedded hypertext links to referenced material. The electronic version of this article is a simple example: references within the document can be followed quickly; for example, from the table of contents to section text. When more documents are available in electronic archives, it will be possible to embed links to more external references as well, as we have done where possible. For example, some research working papers archived by the Economics Working Papers Archive project embed references to other papers stored in the archive, making it possible to simply click on a reference and retrieve a copy.

2. Dynamic commentary. Many authors have puzzled about the interaction between electronic publishing and peer review. The main conflict observed is that the peer review process in most disciplines is quite lengthy and defeats some of the publication timeliness that can be gained by electronic publication and distribution. One novel theme that has emerged is that the peer review process may be replaced in part by dynamic, public commentary and response $[14,15]$. Readers could post comments and critiques directly to the archive where an article is stored; authors could reply. In response to some comments, revised versions of a paper might be posted. Thereby, the review process might be more open, inclusive, timely, and dynamic.

3. Social filtering. One of the obvious impacts of widespread communication networks is that the geography of community can change. One opportunity provided by virtual communities is the application of networks of like-minded people to the problem of information filtering. Every scholar faces the problem of selecting which articles to read from the vast flow of new material [16]. Social filtering systems collect the ratings of networked users and then, based on some form of cluster analysis, dynamically match one user's preferences to the preferences of others to prepare recommendations. For example, Professor X is matched to 10 other professors who have given similar ratings on articles they have mostly all read; the system then recommends to Professor X a previously unread article that the match group has liked. Such a system might, for example, supplement asking only one's local colleagues for advice. Firefly is a working example of a social filtering system (providing recommendations on audio recordings and films). 


\section{PEAK: A FIELD TRIAL}

The University of Michigan has agreed with Elsevier on a pricing field trial, "Pricing Electronic Access to Knowledge" (PEAK). This negotiated trial permits Michigan to provide a host service for 3 years (1996-1998) of all the approximately 1,200 Elsevier Science scholarly titles. Once the trial is under way, articles will become available as quickly as they do for any Elsevier Electronic Subscriptions customer, which is to say, within a few weeks of the mail distribution of the print-on-paper version. Michigan will provide Internet-based delivery to participants in the trial, which will include users both on and off campus. The University of Michigan has substantial experience in the provision of high-bandwidth host service for large volumes of scholarly material. The PEAK project will be implemented by the same team responsible for the technical aspects of the NSF/ARPA UM Digital Library project and the production JSTOR project. For example, JSTOR provides access to the entire historical (pre-1990) corpus of material from 18 journals spanning economics, history, political science, population, and ecology (the earliest issue available dates to 1886). Approximately 100 titles will be available within 2 years, with about a dozen new fields represented. Although there are far more titles in the Elsevier corpus, the run lengths will be considerably shorter. From its experience with JSTOR and other projects, the University of Michigan has developed a full digital production service and currently hosts more than a terabyte of indexed document data on high-speed disk systems. (The University of Michigan was also one of the original host sites and developers of TULIP, The University Licensing Project, sponsored by Elsevier Science.)

For PEAK, Michigan will create a variety of access models and administer a pricing system. The agreement is designed explicitly to support experimental field research; thus, there will be experimental variation in the bundles and prices offered to clients. In this section we shall describe in some detail the structure of the experiment. There are three major design components:

1. Economic design: Specification of the product bundles and the price structure.

2. Experimental design: Implementation of the economic design to obtain statistically informative data.

3. Technical implementation.

\section{Economic Design}

Electronic access directly provides the opportunity to unbundle and rebundle scholarly literature. A print-on-paper journal is a bundle of issues, each of which is a bundle of articles and other items, each of which is a bundle of bibliographic information, an abstract, references, text, figures, and so forth. It is often straightforward (although it does not necessarily cost less) to rebundle any of these elements in different ways when the source material is archived in electronic form. For example, one might obtain all abstracts matching a given keyword search, all citations appearing in a particular article, or just the bibliographic headers from the articles appearing in a given year.

From the beginning, the PEAK project was designed to explore bundling alternatives as well as pricing structures. The specification of product bundles turns out to be a difficult task because the space of possible bundles is extraordinarily large, even if each component of a document is treated as identical across documents (e.g., do not define articles by two different authors to be different commodities for the purpose of bundling). To see this problem, consider bundles defined over just three possible dimensions for electronically accessed scholarly documents:

1. article component (abstract, references, text, etc.), 


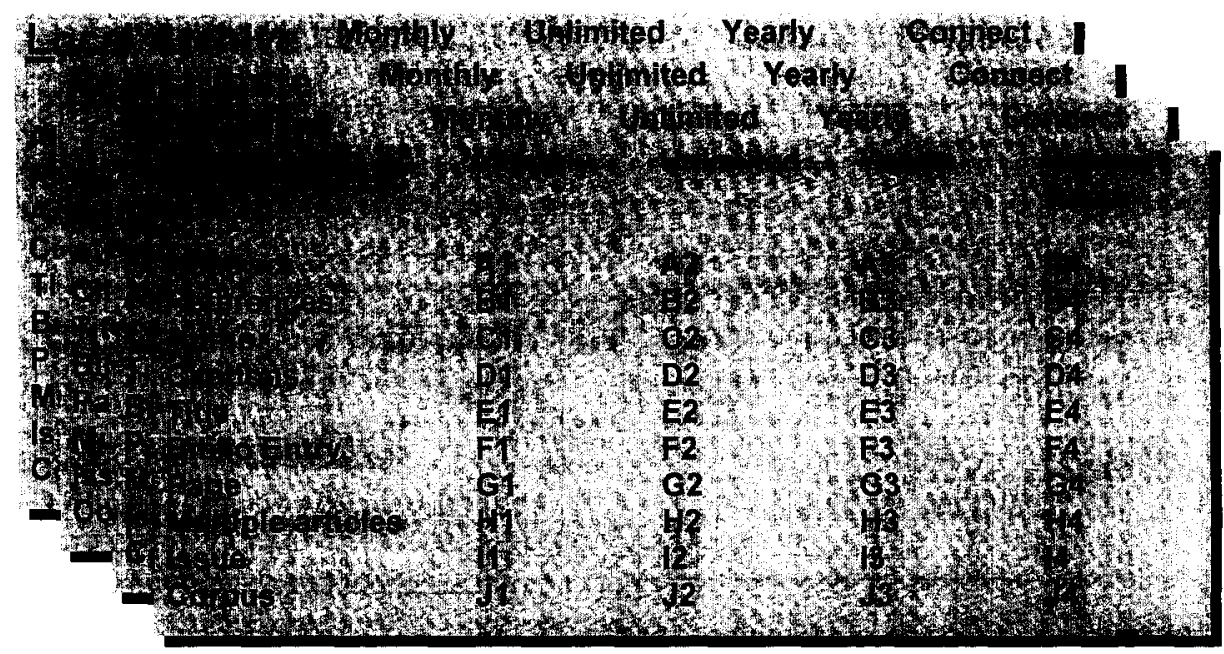

Figure 2. Hypothetical bundling possibilities.

2. time limit on usage (unlimited, per use, per year, etc.), and

3. usage rights (read only, read and print, etc.).

From a rather simple population of the matrix of possibilities, we can postulate 160 possible different bundles (Figure 2) before even specifying different bundle quantities. For example, we might offer a 1-year right to read only $\mathrm{N}$ abstracts. If bundles were priced differently for, say, $N=\{1,10,100$, unlimited $\}$, then the space increases to 640 possible bundles.

Although an explicit goal of the field trial was to explore new opportunities afforded by electronic access, feasibility constraints led to a rather limited selection of bundle types to implement. One important constraint is experimental variation: with a somewhat limited number of different observational units, we cannot obtain sufficient variation to explore very many bundle types. A second constraint is customer acceptance: although this is being operated as a research project by the University of Michigan, the experimental subjects are operational research libraries and individual users who must find the offerings palatable enough for participation to be worthwhile. After numerous meetings with library collection experts and potential participants, the project team decided on three bundles to offer:

1. Per article. Users can purchase unlimited access to a specific article for a fixed price. Standard monopoly analysis shows how to calculate the optimal tariff. The monopolist must produce a level of output that is less than the Pareto efficient amount. In this sense, this scheme will provide an inefficient level of output.

2. Traditional subscription. Users can purchase unlimited access to a set of articles designated as a journal volume by the publisher. These volumes will correspond to the Elsevier print-on-paper journal titles.

3. Generalized subscription. Users can purchase unlimited access to a set of $\mathrm{N}$ articles selected by the user. (The number $\mathrm{N}$ will correspond approximately to the average number of articles, 
by discipline, included in a traditional subscription.) Users can purchase additional increments of $\mathrm{N}$ articles.

The time duration for each of the product bundles is the life of the project +1 year [17]. The usage rights for a document will generally be the same as those for an Elsevier article distributed as print on paper (e.g., U.S. users can print a copy for personal archival purposes, but may not redistribute it further except as provided under the fair use doctrine).

The first and second products are intended to match as closely as possible the best known traditional product bundles [18]. This conservatism should assist in customer acceptance of the trial and allow better comparisons between electronic and print-on-paper experience. The third option is more novel. The generalized subscription is designed to test the opportunity provided by unbundling and rebundling without straying too far from the other product bundles. Limiting product variations to only one dimension will improve statistical inference about the effects of the different bundling schemes. Although the planned product bundles do not deviate far from traditional bundles, they do permit some interesting user choices. In particular, generalized subscriptions allow users to prepay and thus obtain the administrative advantage of budget predictability, yet also allow users the flexibility to choose only articles they want. Indeed, users can bundle articles across journals, and even across traditional disciplines. This shares the risk of paying for unwanted articles with the publisher. Consequently, the value per article accessed should generally be higher to the user than under a traditional subscription, and the per article average price can be correspondingly higher for generalized subscriptions. In short, users trade off an up-front commitment against the benefits of greater customization and the ability to select articles post-publication. Publishers gain by having a significant revenue stream that is predictable and by direct feedback on which articles, from across several journals, readers value most highly.

Recall that the literature on bundling has primarily focused on whether sellers would prefer pure unbundling, pure bundling, or mixed bundling (offering buyers a choice of bundling or unbundling). Our product design and experimental implementation will provide observations on all three types. Some customers will be offered only a per article (pure unbundling) service. Others will be offered only a subscription (pure bundling) service. Still others will have a choice between subscription or per article pricing. However, the products are more complex than those studied thus far in the bundling literature. The differences are largely due to our attempt to maintain plausible comparability to existing print-onpaper offerings while still designing a controlled experiment. For example, our "'mixed bundling" is more general than the form studied in the literature. Customers do not need to choose just subscriptions or alternatively individual articles; a customer might purchase some subscriptions and supplement them with per article purchases. This feature highlights the other necessary complexity: the fact that subscriptions are actually "sub-bundles." In the papers by Chuang and Sirbu [19] and Bakos and Brynjolfsson [20], only one bundle at a time is considered, which consists of either all or a subset of all articles. In practice, publishers offer several bundles, each as a different journal title. Sizable publishers never limit their bundles to a single, all-article bundle. Thus, the value of per article and mixed bundling to the provider will necessarily be conditional on the particular set of sub-bundles (journal titles) the publisher offers [21].

The variety of nonlinear pricing structures is essential unbounded: any nonlinear, monotonically increasing relationship between total payment and quantity (of something) purchased is admissible. Although a field trial offers some possibility to explore the space of pricing structures, we again face feasibility and participation constraints. In particular, because we are also varying product bundles, the number of different pricing schemes that we can implement and still obtain sufficient data for statistical inference is very limited. Within the class of general nonlinear pricing schemes, a large number have been specifically studied and implemented in various industries. These are 


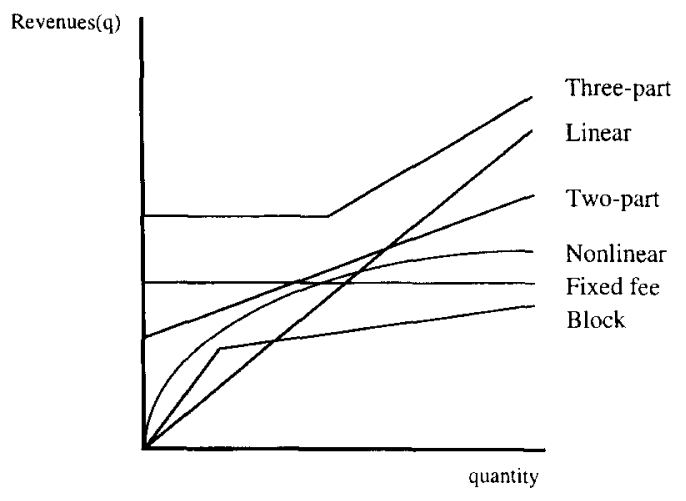

Figure 3. Various nonlinear pricing schemes.

illustrated in Figure 3, which shows the relationship between revenues and quantity for a linear scheme, second-degree price discrimination (block pricing), a two-part and a three-part tariff, a fixed fee, and a generic nonlinear scheme.

The project team plans to implement three-part tariff pricing (Figure 4). There is an entry fee, or up-front payment merely to participate. For that fee, the user obtains a fixed amount of access with no additional charge, with the quantity specified by a breakpoint. After reaching the breakpoint quantity of usage, incremental access is charged at a flat per unit price. Note that a three-part tariff can be applied to any of the above product bundles: the bundle type determines the appropriate measure of usage quantity. For example, with traditional subscriptions, a library might pay an initial fee that grants it rights to 10 subscription titles; for each additional subscription there is a fixed additional charge. The structure would be similar for generalized subscriptions, or per article. The three-part tariff is a rather general structure, with three degrees of freedom. It encompasses two-part tariffs (set the breakpoint to zero), fixed fee (set the breakpoint to infinity),

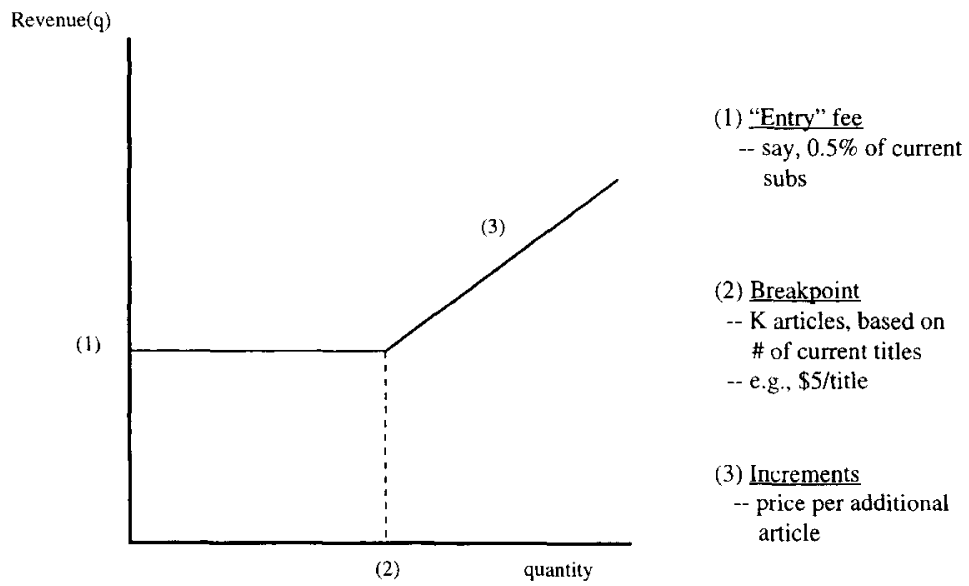

Figure 4. Three-part tariff explained. 
and linear pricing (set the entry fee and breakpoint to zero). When the number of participants is identified, the project team will determine which of the three parameters should be subject to experimental variation in order to estimate the responsiveness of user demand to different pricing structures. It is also important to recognize that the distinction between bundling and nonlinear pricing is not always clear. For example, a user might combine various bundles to construct its own three-part tariff by, say, purchasing five generalized subscriptions (to obtain $5 \mathrm{~N}$ articles at a fixed, up-front price), and then purchasing additional articles at the per article price.

\section{Experimental Design}

The PEAK field trial provides an unprecedented opportunity for exploring bundling and nonlinear pricing opportunities afforded by electronic access. The key research objective, however, is the ability to generalize to other user populations and other scholarly materials. Experimental design considerations are therefore paramount and impose significant constraints on the range of bundling and pricing schemes than can be studied. The fundamental principle of experimental design is that we learn from variation: how do users respond differently when confronted with different alternative bundles or price structures? To obtain a sufficiently rich set of observations to draw inferences from the effects of design parameter variation, we must significantly restrict the number of dimensions that vary. These concerns were reflected in the discussion of bundles and price structures above. There are a number of other interesting features of the experimental design that we describe below.

1. Product diversity. Elsevier is making available approximately 1,200 different journal titles for the trial. This corpus includes titles in virtually every academic discipline. The style, quality, price, and other features of these journals cover a very wide range. Further, scholarly usage styles appear to differ significantly across disciplines. Therefore, product diversity potentially creates a source of difficult-to-control nonexperimental variation. To limit this problem, the experimental design calls for limiting the trial to a few disciplines in which Elsevier titles have an especially strong presence: engineering, medical science, and economics [22].

2. Customer diversity. Scholarly journals have narrow, specialized audiences. Even within a community as large as the University of Michigan (some 30,000 students, of whom about 10,000 are in graduate school, and about 3,200 research faculty), there are likely to be only a few readers for many speciality journals. Only a fraction of these are likely to participate in an electronic access trial. Therefore, in order to obtain sufficient participation and usage, the project was designed to include clients from a number of organizations outside the University of Michigan. The preliminary participant list includes other research universities and industrial research facilities. There may also be participating 4-year undergraduate colleges. Although the sample size of users for each subset of literature is increased by including multiple institutions, broader scope also creates design problems. There will be greater diversity in physical facilities, marketing and communications to participants, and institutional arrangements. The latter is of special concern. Participation in the trial will occur both by institutional and individual decision makers. For example, both will be able to subscribe, and both will be able to purchase on a per article basis. The behavior of a rational and well-informed individual user will be conditioned on the behavior by her associated institution [23]. For example, an individual might subscribe to a journal only if the organization's library does not. This complication is probably unavoidable and will pose challenges for the proper statistical analysis of the results. 
3. Duration and learning. This trial involves a rather novel access mode for scholarly literature. Although Michigan has substantial institutional experience from TULIP, JSTOR, UMDL, and other projects, most individual users of scholarly literature on campus have little or no experience with electronic access to traditional scholarly journals. Users at the other participating institutions-both individual and institutional-are likely to be even less experienced. The learning process will complicate efforts to uncover generalizable results. The project team will actively educate potential users about the trial, the products, and the pricing. Further, we will be collecting data over a 2 - to 3 -year period and, thus, will have some chance to isolate learning effects. Although not really part of the experimental design, there are also a number of technical issues that must be overcome to complete the implementation of the PEAK project. These include the implementation of an accounting system and a payment mechanism, and user authentication to the access system. As much as possible we are relying on off-the-shelf or already implemented local solutions.

\section{CONCLUSION}

In the introduction period of electronic publishing, pricing of electronic products will be linked more to the print prices due to the uncertainties involved. But, Elsevier Science intends to work with an electronic access pricing model in the future that will be based on:

1. the value of the functionalities for a specific customer group,

2. the amount of users making use of the products, and

3. how often each user uses the product.

In addition, Elsevier is developing advanced electronic applications that will be offered in various bundles with traditional journal access. Thus, the future-from many publishers-appears likely to include nonlinear and differential pricing, as well as innovative production bundling. In order to structure prices around the value components above, a publisher needs to learn about consumer preferences and usage. To this end, Elsevier Science has entered the agreement with Michigan to implement a field experiment on bundling and nonlinear pricing. Other experiments with different host institutions are likely in the future. The space for electronic access product bundling and pricing structures is immense. Many field trials will be required to explore even a limited set of important alternatives.

\section{NOTES}

1. Bakos, Y., and E. Brynjolfsson. "Bundling Information Goods: Pricing, Profits and Efficiency," University of California, Irvine Working Paper, 1996, pp. 1-30. Presented at the Conference on Economics of Digital Information and Intellectual Property, Harvard University, January 1997.

2. Chuang, J., and M. Sirbu. "The Bundling and Unbundling of Information Goods: Economic Incentives for the Network Delivery of Academic Journal Articles," Presented at the Conference on Economics of Digital Information and Intellectual Property, Harvard University, January 1997.

3. MacKie-Mason, J., and J. F. Riveros. "Economics and Electronic Access to Scholarly Information," Presented at the Conference on Economics of Digital Information and Intellectual Property, Harvard University, January 1997. Includes a brief survey of the state of the theoretical literature on bundling and some of its gaps.

4. Kling, Rob, and Roberta Lamb. "Analyzing Alternate Visions of Electronic Publishing and Digital Libraries." Scholarly 
Publishing: The Electronic Frontier, eds. R. Peek and G. Newby. Cambridge: MIT Press, 1996. Offers an insightful discussion of utopian discourse on information technology and electronic publishing.

5. Harnad, Stevan. "Implementing Peer Review on the Net: Scientific Quality Control in Scholarly Electronic Journals," Scholarly Publishing: The Electronic Frontier, eds. R. Peek and G. Newby. Cambridge: MIT Press, 1996.

6. Odlyzko, Andrew. "Tragic Loss or Good Riddance? The Impending Demise of Traditional Scholarly Journals," International Journal of Human-Computer Studies, 42 (1995), 71-122.

7. Fisher, Janet. “Traditional Publishers and Electronic Journals," Scholarly Publishing: The Electronic Frontier, eds. R. Peek and G. Newby. Cambridge: MIT Press, 1996. A nice overview of the value-added functions provided by publishers.

8. Hayes, Brian. "'The Economic Quandary of the Network Publisher,' Scholarly Publishing: The Electronic Frontier, eds. R. Peek and G. Newby. Cambridge: MIT Press, 1996. Nicely characterizes the publisher's role in bringing readers to authors.

9. The competitive equilibrium result assumes that there are no externalities. This means that the amount of publishing services received by any one agent does not directly affect the well being of any other agent. A typical externality is water pollution: the more that I produce, the worse the conditions for downstream residents.

10. Odlyzko, pp. 71-122.

11. Some publishers are sufficiently concerned with the effect of electronic distribution that they are treating posting of drafts and working papers on the Internet as prior publication and are refusing to consider such articles for their journals. Most American Psychological Association journal editors have adopted this policy, as have Neuroscience and The New England Journal of Medicine.

12. Most familiar pricing is "linear." That is, revenue increases linearly with quantity purchased, because revenue $=$ price $x$ quantity, and the price is a constant value for each quantity unit. Nonlinear pricing refers to a very broad class of schemes in which revenue increases nonlinearly with price. Quantity discounts and two-part tariffs (entry fee + per unit fee) are examples.

13. Users have found ways to arbitrage around some of the variable pricing conditions. For example, users have exploited "free format" features (free online records to test search strategies) by downloading 600-700 answers in free format, then choosing relevant citations offline and logging back in for retrieval.

14. Harnad, Stevan. "Scholarly Skywriting and the Prepublication Continuum of Scientific Inquiry," Psychological Science, 1 (1990), 342-343.

15. Harnad, "Implementing Peer Review on the Net."

16. Odlyzko points out that about half of all scholarly literature ever published has been published in just the last 10 years.

17. The University of Michigan and Elsevier anticipate that access to paid-for documents and bundles might persist beyond the life of the original project agreement, but that is not guaranteed.

18. Pay per article is traditionally available through at least three vehicles: by paying a per article royalty to the Copyright Clearance Center; by purchasing an article from a document delivery service (which in turn remits royalties); or, when fair use is invoked, by paying the cost of photocopying.

19. Chuang, J., and M. Sirbu.

20. Bakos, Y., and E. Brynjolfsson.

21. Of course, the selection of the number of sub-bundles, or journal titles, and the guidelines for their specialty content are endogenous. At a given point in time, mixed bundling might be superior to "traditional subscription only" because reader tastes are sufficiently aligned with journal boundaries. If the publisher responds to this mismatch, the relative value of traditional subscriptions may increase.

22. In 1996, the University of Michigan subscribed to approximately 69 engineering titles at an average cost of about $\$ 1,000 /$ title, 13 economics titles ( $\$ 900 /$ title), and 134 medical titles $(\$ 1,200 /$ title).

23. The causality may also run in the opposite direction, of course, but we expect that during the relatively short duration of this trial the purchasing decisions of the institution will likely be relatively predetermined with respect to individual decisions. Over a greater time horizon, the chance that library purchasing would respond to individual choices would likely increase.

\section{ADDITIONAL REFERENCES}

1. Adams, W., and Yellen, J. "Commodity Bundling and the Burden of Monopoly," Quarterly Journal of Economics, 90 (1976), 475-498.

2. Deaton, A., and John Muellbauer. Economics and Consumer Behavior. Cambridge: Cambridge University Press, 1980.

3. Gorman, W. M. "Separable Utility and Aggregation," Econometrica, 27 (1959), 469-481.

4. Katz, M. "Nonuniform Pricing, Output and Welfare under Monopoly," Review of Economic Studies, 50 (1983), 37-56.

5. MacKie-Mason, J., and D. Lawson. "Local Telephone Calling Demand When Customers Face Optional and Nonlinear Price Schedules," Working Paper, (1993): 1-33. 
6. McAfee, R., J. McMillan, and M. Whinston. "Multiproduct Monopoly, Commodity Bundling and Correlation of Values," Quarterly Journal of Economics, 114 (1989), 371-384.

7. Schmalensee, R. "Commodity Bundling by a Single Product Monopolist," Journal of Law and Economics, 25 (1982), $67-71$.

8. Stigler, G. "United States vs. Loew's Inc.: A Note on Block Booking," Supreme Court Review, (1963), $152-157$.

9. Tirole, J. The Theory of Industrial Organization. Cambridge: MIT Press, 1988.

10. Varian, H. Microeconomic Analysis. New York: Norton, 1992.

11. Wilson, R. Nonlinear Pricing. New York: Oxford University Press, 1993.

12. Zahray, W., and M. Sirbu. "The Provision of Scholarly Journals by Libraries via Electronic Technologies: An Economic Analysis," Information Economics and Policy, 4 (1990), 127-154. 